\title{
Effects of process parameters on core-back foam injection molding process
}

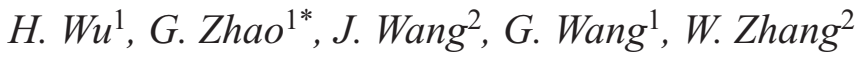 \\ ${ }^{1}$ Key Laboratory for Liquid-Solid Structural Evolution and Processing of Materials (Ministry of Education), Shandong \\ University, Jinan, 250061 Shandong, PR China \\ ${ }^{2}$ Qingdao Hisense Mould Co., Ltd. Qingdao, 266114 Shandong, PR China
}

Received 11 October 2018; accepted in revised form 3 December 2018

\begin{abstract}
Experiments of a new core-back foam injection molding process are described in this paper wherein the blowing agent content $[\%]$, mold temperature $\left[{ }^{\circ} \mathrm{C}\right]$, shot size $[\mathrm{mm}]$, injection speed $[\mathrm{mm} / \mathrm{s}]$, holding pressure $[\mathrm{MPa}]$, holding time $[\mathrm{s}]$ and core-back rate $[\mathrm{mm} / \mathrm{s}]$ were taken as single variables, respectively. The effects and mechanisms of the above parameters on the molding process were studied. The relationships of the parameters with the mechanical properties and the weight reduction effect of the specimens were analyzed. The results show that the effect of blowing agent content, mold temperature, shot size, injection speed and core-back rate in the new method is similar to that of conventional core-back foam injection molding. However, the first stage holding pressure and holding time of the holding process in the secondary filling stage which the new method peculiarly possesses play the same role as shot size and injection speed in conventional foam injection molding, and the second stage holding pressure and holding time play the role of pressure holding in conventional foam injection molding. Compared with the conventional foam injection molding method, the specimens obtained by using the new method have higher weight loss rate, better mechanical properties, and higher specific strength.
\end{abstract}

Keywords: mechanical properties, core-back, injection molding, foam, ploypropylene

\section{Introduction}

Resource shortage and environmental pollution are the main problems faced by the development of manufacturing industry [1]. The use of foamed materials is the main way to achieve lightweight. Polymer foams, as a kind of commonly used lightweight foamed materials, have many advantages, such as high porosity and internal specific surface area, outstanding heat insulation, excellent sound insulation, low dielectric constant, excellent energy absorption and buffer capacity. Therefore, polymer foams have broad application prospects in sustainable development, energy saving, and emission reduction.

The commonly used polymer foaming methods include batch foaming, bead foaming, extrusion foaming, and foam injection molding. The basic process of these foaming methods can be grouped into four stages. The first stage is to obtain the gas/polymer homogeneous system, where batch foaming and bead foaming generally place the polymer in the autoclave and fill it with high-pressure gas, while extrusion foaming and injection foaming generally mix the gas with the plasticized polymer melt in the screw. The second stage is to induce cell nucleation, the gas/ polymer homogeneous system is generally depressurized or heated to render the system instable and generate phase separation, inducing cell nucleation. The third stage is that the gas continues to separate and diffuse from the gas/polymer homogeneous system, causing the nucleated cells to grow. The fourth stage is that when the system temperature drops to a certain extent, the polymer melt solidifies, the cells 
cannot continue to grow, and the cell structure is finally fixed [2].

In conventional foam injection molding process, because the cavity space of the mold is fixed, the space needed for the cell growth after nucleation is mainly provided by the polymer cooling contraction or short shot. However, the volume of the polymer cooling contraction is small, generally, the contraction of crystalline polymer is $1.0-3.0 \%$ and amorphous polymer is only $0.4-0.8 \%$. It can be seen that the space obtained by the polymer cooling contraction is very limited. In addition, although larger space can be obtained by short shot, but due to the low pressure at the melt flow front, the melt near the flow front tends to be over foamed, resulting in uneven cell size and distribution in the plastic parts. These problems limit the production and application of foam injection molding to a certain extent.

In the field of foam injection molding, many scholars have carried out a lot of research work on conventional physical foam injection molding [3-6], core-back physical foam injection molding [7-10] and gas counter pressure (GCP) foam injection molding [9-13]. Core-back foam injection molding [1425 ] is to inject gas/polymer homogeneous system into the mold cavity first, and use high holding pressure to eliminate the cells generated in the filling process, then open the mold or withdraw the mold core at a certain distance to make the melt foam. It can provide enough space for the growth process after cell nucleation during the foam injection molding process, so as to obtain plastic parts with higher porosity and relatively uniform internal cell size and distribution. Ishikawa and Ohshima [26] used core-back foam injection molding to obtain the plastic parts with a cell density of about $2.3 \cdot 10^{10} \mathrm{cells} / \mathrm{cm}^{3}$, and used visual mold to study the foaming behavior of core-back foam injection molding. The results showed that the foaming process of core-back foam injection molding is similar to that of batch foaming, and the results of batch foaming can be used to guide the foaming process of core-back foam injection molding. Wang et al. [27] prepared $\mathrm{PP} / \mathrm{CNF}$ nanocomposite foams with an ultra-high expansion ratio up to 18 fold using core-back foam injection molding, and studied the crystallization behavior of the PP/CNF nanocomposites. The results showed that at this super high foaming rate $\mathrm{PP} / \mathrm{CNF}$ nanocomposite foams not only contain the traditional shish-kebab crystal of PP, but also shish-kebab crystals of CNF. Shaayegan et al. [1] obtained the PS foams with a cell diameter of about $35 \mu \mathrm{m}$ and cell density of $10^{7} \mathrm{cell} / \mathrm{s} / \mathrm{cm}^{3}$ orders of magnitude by using core-back foam injection molding, and studied the effect of injection pressure and holding time on the cell structure before core-back. The results showed that in order to eliminate the cells formed in the melt before core-back, pressure holding is needed, and the holding time increases with the decrease of injection pressure, but excessive holding time will cause the cell nucleation again due to the cooling contraction of the melt, resulting in the final failure to obtain good foams. Wang et al. [28] obtained the PLA/graphite nanocomposites foams with a cell diameter of about $12 \mu \mathrm{m}$ and cell density of $1.8 \cdot 10^{8} \mathrm{cells} / \mathrm{cm}^{3}$ by using core-back foam injection molding, and studied the electromagnetic shielding and mechanical properties of the composite. The results showed that the PLA/graphite nanocomposites foamed by core-back foam injection molding have good electromagnetic shielding properties and excellent mechanical properties. Wang et al. [29] obtained the PP foams with a cell diameter of about $7 \mu \mathrm{m}$ and cell density of $1.6 \cdot 10^{9}$ cells $/ \mathrm{cm}^{3}$ by using core-back foam injection molding with air as blowing agent. The results showed that cell structure and melt properties of PP are changed when air is used as blowing agent, the foaming process was similar to reactive foaming, resulting in better cell structure. Core-back foam injection molding usually uses physical blowing agents such as supercritical $\mathrm{CO}_{2}$ and supercritical $\mathrm{N}_{2}$, which have strong foaming ability. However, when using this kind of physical blowing agent for foam injection molding, it is necessary to add a set of expensive supercritical fluid generating device, and modify the screw and barrel of injection molding machine, which greatly increases the cost of equipment [30]. Compared with the physical blowing agent, the chemical blowing agent for foam injection molding does not need addition of gas generating device, nor needs modification of the injection molding machine, thus significantly reduces the cost of the equipment. However, in core-back foam injection molding experiment, the foaming ability of chemical blowing agent was lower than that of physical blowing agent. The melt could not be foamed smoothly when using chemical blowing agent in conventional core-back foam injection molding, and the plastic parts could not completely fill the cavity after core-back [31]. This restricts the application of coreback foam injection molding to a certain extent. 
In the previous studies, a new core-back foam injection molding method were proposed. This method firstly injects the polymer melt into the mold cavity by conventional injection method, and then carries out core-back immediately, which makes the melt form a special skin structure with a closed cavity. Then the new melt is filled again into the internal cavity of the skin structure by pressure holding and foam. In this paper, based on this new core-back chemical foam injection molding method, the effects of blowing agent content $[\%]$, mold temperature $\left[{ }^{\circ} \mathrm{C}\right]$, shot size $[\mathrm{mm}]$, injection speed [ $\mathrm{mm} / \mathrm{s}]$, holding pressure $[\mathrm{MPa}]$, holding pressure time $[\mathrm{s}]$ and core-back rate $[\mathrm{mm} / \mathrm{s}]$ on the forming process were studied. The influencing mechanism of the parameters on plastic parts molding process was revealed. The relationship between the parameters and mechanical properties and relationship between the parameters and weight reduction effect of plastic parts were analyzed. Compared with the conventional foam injection molding method, the specimens obtained by this new method have higher weight loss rate, better mechanical properties, and higher specific strength.

\section{Experiment and characterizations \\ 2.1. Experiments design}

Figure 1 gives the principle and basic process of melt filling of the core-back foam injection molding used in this paper. The whole process includes conventional injection stage, core-back stage, and the newly added secondary filling stage. In the conventional injection stage, the core of the mold is always at the front end. The melt filling process in this stage is the same as that of the conventional foam injection molding. During the core-back process, the melt foams immediately and forms a special 'skin' structure with a cavity under the negative pressure of the mold cavity wall. Once the core-back is finished, a unique 'secondary filling stage' begins immediately, new melt is filled into the cavity of this special 'skin' structure in this stage. In addition, the gas in the cavity will break through and spill at a weak position of the skin, and is discharged through the exhaust system of the mold [31].

Syndiotactic polypropylene plastics (BJ550), provided by Samsung Total, Korea, was used as an experimental injection material, azodicarbonamide (AC) was used as the chemical blowing agent, a double shaft blade mixer was used to mix the AC blowing agent and polypropylene, and a 180 ton pure electric injection molding machine (J180ADC180H, Japan Steel Work, Ltd) was used as the injection molding machine.

In order to study the effects of blowing agent content $[\%]$, mold temperature $\left[{ }^{\circ} \mathrm{C}\right]$, shot size $[\mathrm{mm}]$, injection speed $[\mathrm{mm} / \mathrm{s}]$, holding pressure $[\mathrm{MPa}]$, holding

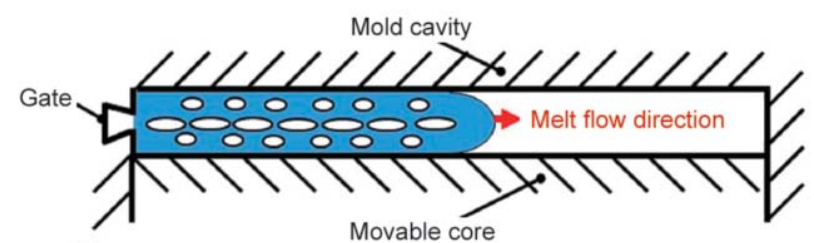

a)

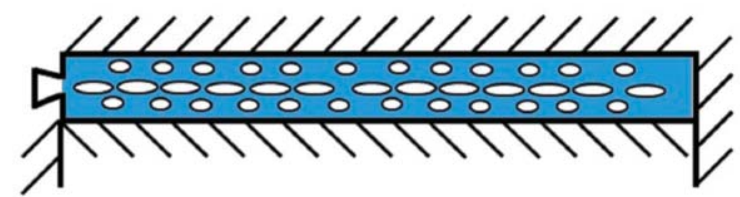

b)

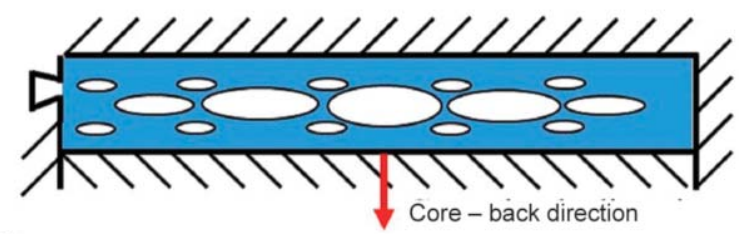

c)
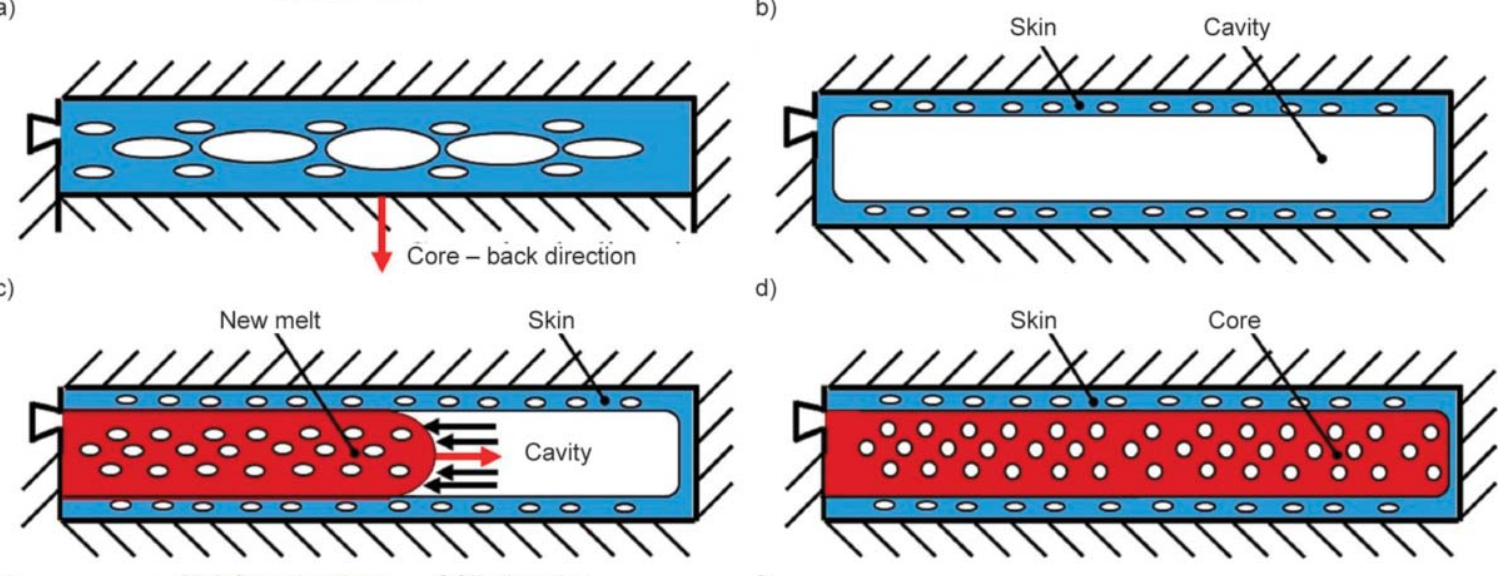

e)

Melt flow direction

GCP direction

f)

Figure 1. Principle and basic process of melt filling of the core-back foam injection molding. Stage I: conventional injection stage, Stage II: core-back stage, Stage III: secondary filling stage [31]. a) conventional injection, b) end of conventional injection, c) core-back, d) end of core-back, e) secondary filling, f) end of secondary filling. 
Table 1. Processing parameters used for the foam injection molding experiments.

\begin{tabular}{|ll|l|}
\hline \multicolumn{2}{|c|}{ Parameters } & \multicolumn{1}{c|}{ Values } \\
\hline AC content & {$[\%]$} & $3,5,7,9$ \\
\hline Mold temperature & {$\left[{ }^{\circ} \mathrm{C}\right]$} & $30,50,70$ \\
\hline Shot size & {$[\mathrm{mm}]$} & $56,58,60,62$ \\
\hline Injection speed & {$[\mathrm{mm} / \mathrm{s}]$} & $95,100,105,110$ \\
\hline First stage holding pressure & {$[\mathrm{MPa}]$} & $0,1,3,5,7$ \\
\hline First stage holding time & {$[\mathrm{s}]$} & $0,0.5,1,1.5,2,2.5,3$ \\
\hline Second stage holding pressure & {$[\mathrm{MPa}]$} & $0,12,18,24$ \\
\hline Second stage holding time & {$[\mathrm{s}]$} & $0,0.5,1$ \\
\hline Core-back rate & {$[\mathrm{mm} / \mathrm{s}]$} & $1,3,5,7,9$ \\
\hline
\end{tabular}

time $[\mathrm{s}]$ and core-back rate $[\mathrm{mm} / \mathrm{s}]$ on the injection molding process, different core-back foam injection molding process parameters were selected, as shown in Table 1, and the corresponding core-back foam injection molding experiments were carried out. In addition, the total core-back distance is $3.5 \mathrm{~mm}$.

\subsection{Characterizations and testing methods}

\subsubsection{Cells structure and skin morphology}

The notch impact specimens were immersed in liquid nitrogen for 15 minutes, then taken out and broken at $33 \mathrm{~mm}$ from the gate to observe the morphology of the skin and cells structure, as shown in Figure 2a. In addition, the 'internal short shot' specimens were prepared by cutting, the cutting position was shown in Figure 2b. A Hitachi SU-70 thermal field emission scanning electron microscopy was used to observe the morphology of the cell structure

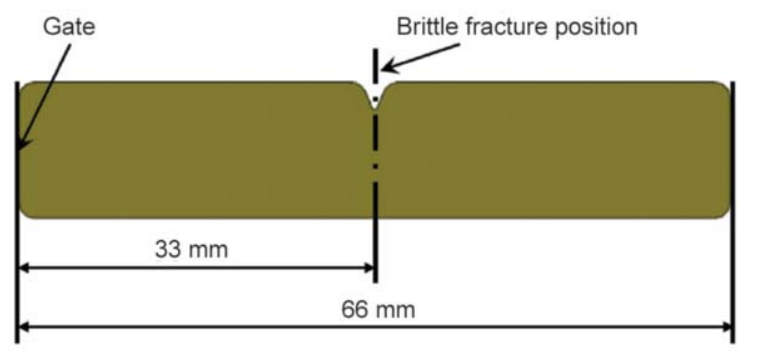

a) and skin, the test voltage range is $5-15 \mathrm{kV}$, and the magnification range is $50-100$ times. The observation surfaces of all specimens were sprayed with gold because polymer materials are insulating materials. The average cell density was calculated by using the following Equation (1) proposed by Kumar [32]:

$N_{\mathrm{j}}=\left(n_{\mathrm{j}} \frac{M^{2}}{A}\right)^{\frac{3}{2}}$

where $N_{\mathrm{j}}$ is the average cell density [cells $\left./ \mathrm{cm}^{3}\right] ; n_{\mathrm{j}}$ is the number of cells observed in SEM photo; $M$ is the magnification factor of the SEM photo; $A$ is the SEM photo area of the selected observation area $\left[\mathrm{cm}^{2}\right]$. Three specimens were taken at the same location, and the average cell diameter and cell density observed by SEM were taken as the mean diameter and average cell density.

\subsubsection{Observation of specimen filling rate}

The notch impact specimens were cut to observe the position and shape of the internal flow front inside the plastic parts. The initial specimen is shown in Figure $3 \mathrm{a}$. The specimen is cut from the end away from gate in the opposite direction of melt flow until to the front part of the internal flow front, as shown in Figure $3 \mathrm{~b}$; and finally a specimen with a complete profile of the internal flow front is obtained, as shown in Figure 3c. Measuring the distance from the internal flow front to the gate, then dividing the measured

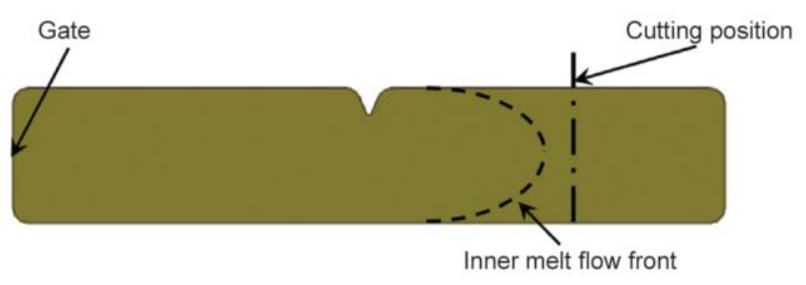

b)

Figure 2. Sampling position for SEM: (a) embrittlement sampling position (b) cutting sampling position.

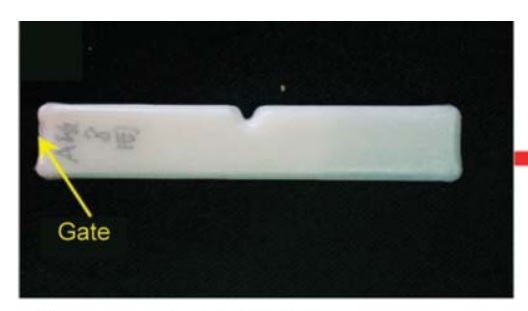

a)

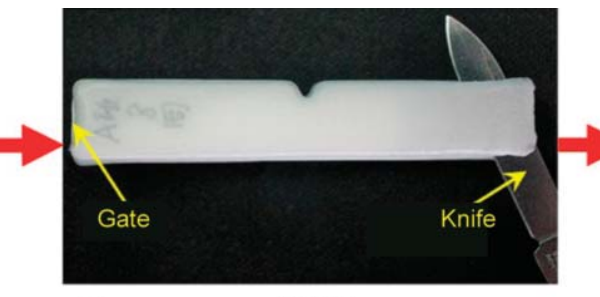

b)

Cutting

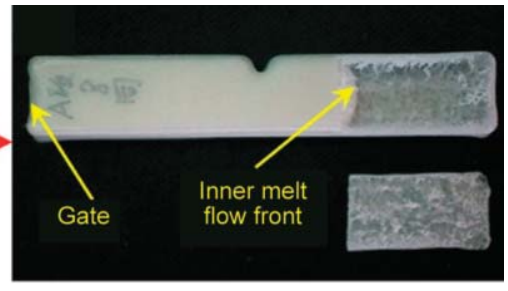

Final specimen

Figure 3. Method for cutting specimens to observe position and shape of internal flow front. a) initial specimen, b) cutting, c) final specimen. 
distance by the total length of the specimen to obtain the filling rate of the specimen.

\subsubsection{Mechanical properties and weight reduction}

A universal electronic test machine (SANS CMT 5105 ) with an extensometer was used to test the tensile strength of the tensile specimens. An Izod type cantilever beam impact test machine was used to test the impact performance of the notched specimens. At least five specimens were tested in each test condition to avoid accidental errors, and the average values were used as the results. In addition, the final values of mechanical properties were divided by the density of the specimens to obtain the specific strength, and used for comparison, so as to improve the intuition and accuracy of comparison.

A high precision solid density tester (DX-120X) was used to measure the density of the specimens, then according to the following formula, the weight loss Equation (2):

$\delta_{\mathrm{i}}=\left(1-\frac{\rho_{\mathrm{i}}}{\rho_{0}}\right) \cdot 100 \%$

where $\rho_{0}$ is the density of the conventional injection molding specimens, when $i=1, \delta_{1}$ and $\rho_{1}$ represent the weight loss rate and density of core-back foam injection molding specimens, respectively, when $i=2$, $\delta_{2}$ and $\rho_{2}$ represent the weight loss rate and density of foam injection molding specimens, respectively.

\section{Results and discussion}

According to the processing parameters shown in Table 1, the core-back foam injection molding experiments were carried out by taking each parameter as single variable.

\subsection{Influence of blowing agent content and mold temperature}

When the blowing agent content is used as the single variable, the other parameters are fixed, where the mold temperature is $50^{\circ} \mathrm{C}$, the shot size is $60 \mathrm{~mm}$, the injection speed is $105 \mathrm{~mm} / \mathrm{s}$, the first stage holding pressure is $5 \mathrm{MPa}$, the first stage holding time is $3 \mathrm{~s}$, the second stage holding pressure is $18 \mathrm{MPa}$, the second stage holding time is $0.5 \mathrm{~s}$, and the core-back rate is $7 \mathrm{~mm} / \mathrm{s}$.

Figure 4 shows the SEM photographs (the location of the photos taken for SEM is in the middle of the specimen) of the specimen's cross section when blowing agent content is 3, 5, 7 and $9 \%$, and the photos of the specimens with 7 and $9 \%$ blowing agent, respectively. It can be seen that when the blowing agent content is 3, 5 and $7 \%$, the cell density of the specimen increases significantly in turn. The calculation shows that when the blowing agent

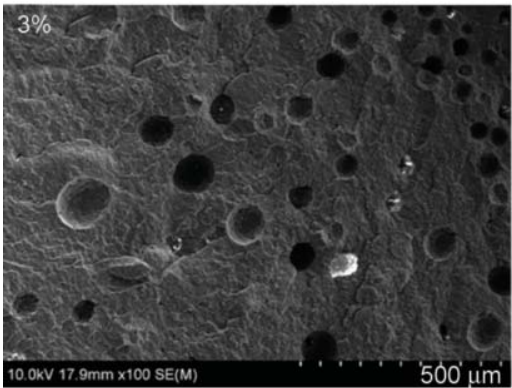

a)

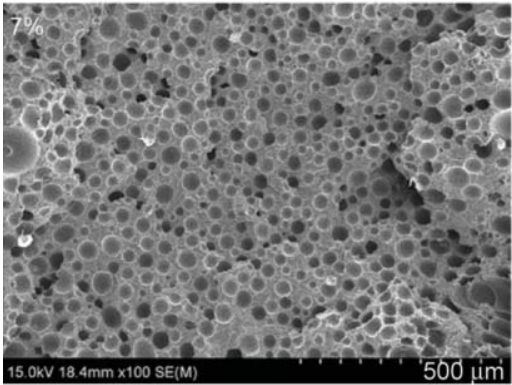

d)

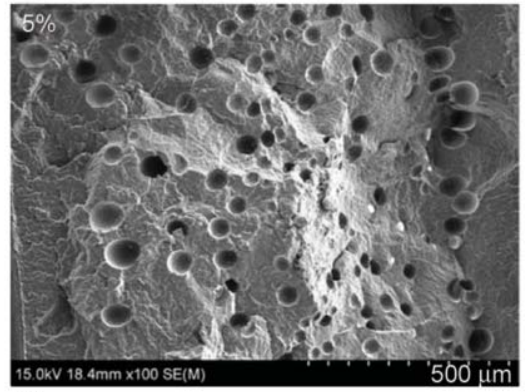

b)

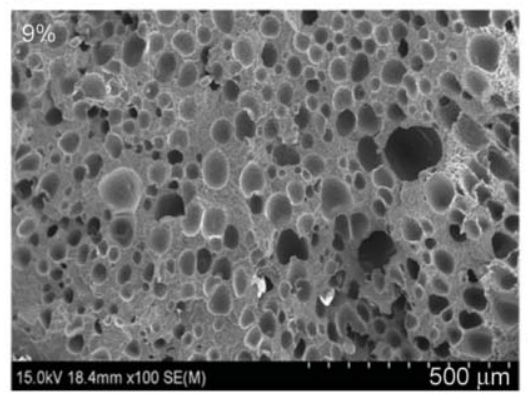

e)
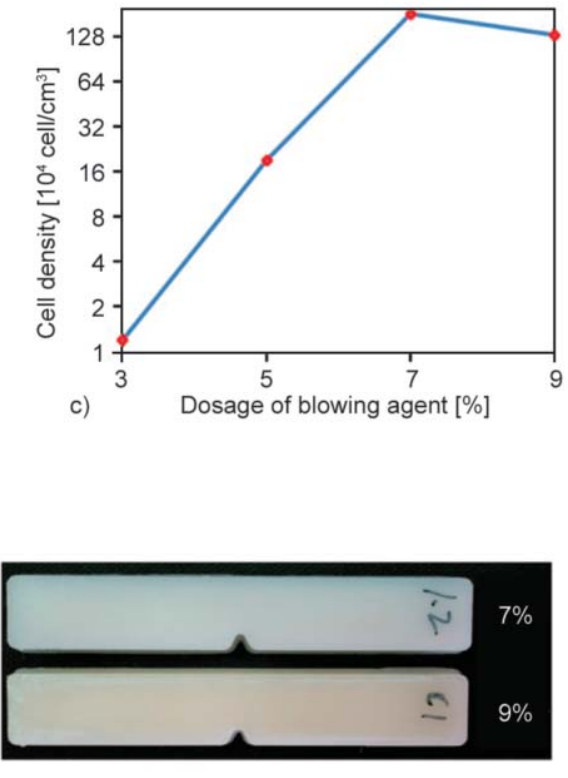

Figure 4. SEM photographs of the specimen's cross section and photos of the specimens with different blowing agent contents. a) SEM photograph with 3\% blowing agent, b) SEM photograph with 5\% blowing agent, c) curve of cell density with different blowing agent content, d) SEM photograph with 7\% blowing agent, e) SEM photograph with $9 \%$ blowing agent, f) specimens with 7 and $9 \%$ blowing agent. 
content is $7 \%$, the cell density of the specimen is $1.8 \cdot 10^{6} \mathrm{cells} / \mathrm{cm}^{3}$, when the blowing agent content is 3 and $5 \%$, the cell density of the specimens is $1.2 \cdot 10^{4}$ cells $/ \mathrm{cm}^{3}$ and $1.9 \cdot 10^{5}$ cells $/ \mathrm{cm}^{3}$, respectively. However, when the blowing agent content is $9 \%$, the cell density of the specimen is only $1.3 \cdot 10^{6} \mathrm{cell} / \mathrm{s} / \mathrm{cm}^{3}$, which is lower than that of the blowing agent content of $7 \%$. This is because the main chemical reaction in the decomposition of azodicarbonamide is exothermic. When the content of the blowing agent is $9 \%$, excessive heat is released from the decomposition of azodicarbonamide, making the melt strength of PP remains at a low level for a period of time, and causing the formed cells to coalesce [33]. It can also be seen from Figure 4 that the color of the specimen with blowing agent content of $9 \%$ is obviously more yellow than that with blowing agent content of $7 \%$. This is because excessive exothermic heat inhibits the decomposition of a part of azodicarbonamide, the undecomposed azodicarbonamide is evenly dispersed into the melt in the barrel. Since the color of azodicarbonamide is yellow, the undecomposed azodicarbonamide plays a similar role to the color master batch, making the appearance of the specimen yellow.

When the mold temperature is used as the single variable, the other parameters are fixed, where the blowing agent content is $7 \%$, the shot size is $60 \mathrm{~mm}$, the injection speed is $105 \mathrm{~mm} / \mathrm{s}$, the first stage holding pressure is $5 \mathrm{MPa}$, the first stage holding time is $3 \mathrm{~s}$, the second stage holding pressure is $18 \mathrm{MPa}$, the second stage holding time is $0.5 \mathrm{~s}$ and the core-back rate is $7 \mathrm{~mm} / \mathrm{s}$.

Figure 5 gives the micrographs and 3D outline of the specimen surface for the mold temperature of 30,50 , and $70^{\circ} \mathrm{C}$, respectively. It can be seen from the micrographs and the corresponding 3D outline that when the mold temperature is $30^{\circ} \mathrm{C}$, there are obvious pits on the surface of the specimen. This is because when the mold temperature is relatively low, the melt cooling is too fast to completely copy the surface of mold cavity, resulting in more surface defects, but when the mold temperature is 50 and $70{ }^{\circ} \mathrm{C}$, the pit defects on the specimen surface have disappeared. In addition, when the mold temperature reaches $50^{\circ} \mathrm{C}$, the replication effect of the specimen on the cavity surface has met the needs of non-high-gloss injection molding. The stripe marks in the micrographs are due to the melt duplicating the scratches on the cavity surface or the scratches on the surface of the plastic parts during storage and transportation.

\subsection{Influence of shot size and injection speed}

When the shot size is used as the single variable, the other parameters are fixed, where the blowing agent content is $7 \%$, the mold temperature is $50^{\circ} \mathrm{C}$,

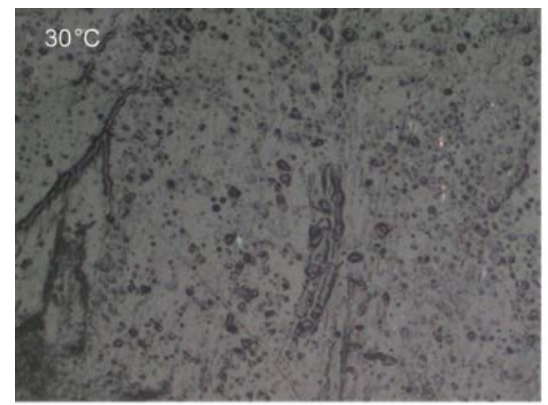

a)

$30^{\circ} \mathrm{C}$

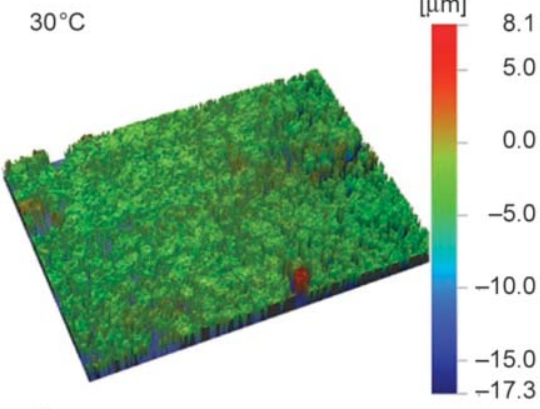

d)

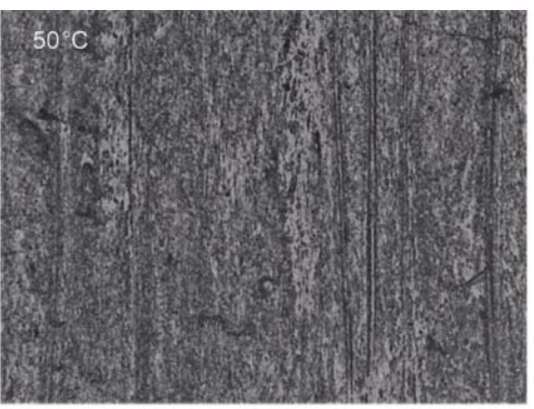

b)

$50^{\circ} \mathrm{C}$

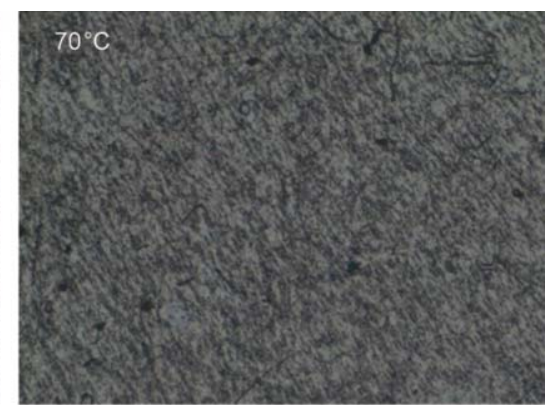

c)

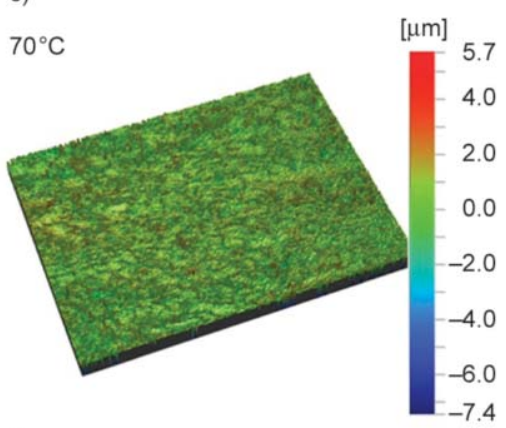

Figure 5. Micrographs and 3D outline of specimen surface at different mold temperatures. a) micrograph at mold temperature of $30^{\circ} \mathrm{C}$, b) micrograph at mold temperature of $50^{\circ} \mathrm{C}, \mathrm{c}$ ) micrograph at mold temperature of $\left.70^{\circ} \mathrm{C}, \mathrm{d}\right) 3 \mathrm{D}$ outline at mold temperature of $30^{\circ} \mathrm{C}$, e) $3 \mathrm{D}$ outline at mold temperature of $\left.50^{\circ} \mathrm{C}, \mathrm{f}\right) 3 \mathrm{D}$ outline at mold temperature of $70^{\circ} \mathrm{C}$. 


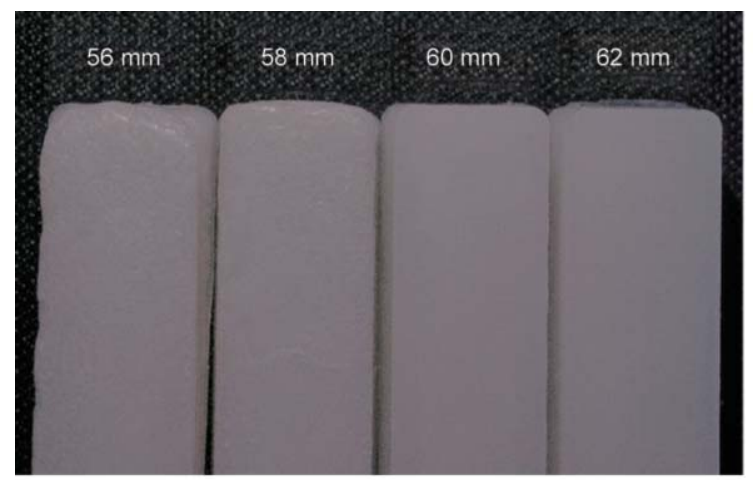

a)

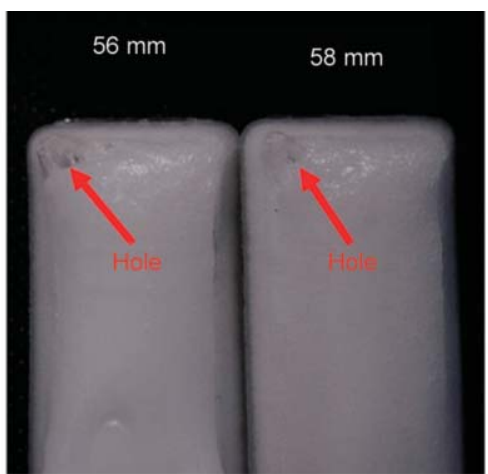

b)

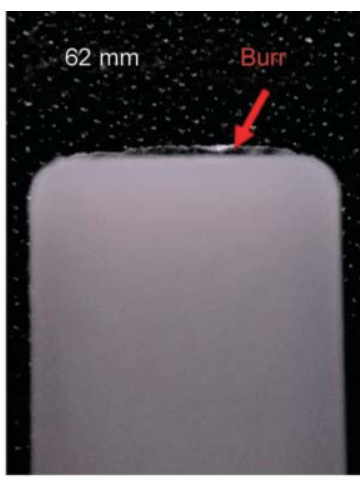

c)

Figure 6. Photos of the specimens at different shot sizes, (a) photos of the specimens, (b) under no holding pressure condition, (c) shot size of $62 \mathrm{~mm}$.

the injection speed is $105 \mathrm{~mm} / \mathrm{s}$, the first stage holding pressure is $5 \mathrm{MPa}$, the first stage holding time is $3 \mathrm{~s}$, the second stage holding pressure is $18 \mathrm{MPa}$, the second stage holding time is $0.5 \mathrm{~s}$ and the core-back rate is $7 \mathrm{~mm} / \mathrm{s}$.

Figure 6 shows photos of the specimens at different shot sizes. Figure 6a shows the appearance of the specimens at shot size of 56, 58, 60 and $62 \mathrm{~mm}$, respectively. It can be seen from the photo that when the shot size is 56 and $58 \mathrm{~mm}$, respectively, the surface of the specimens are rough and have wrinkles. In addition, in the case of no holding, specimens with internal cavity but intact shape can be obtained by using new core-back foam injection molding. However, as shown in Figure 6b, the shapes of specimens with shot size of 56 and $58 \mathrm{~mm}$ are incomplete, collapse occurs, and there are holes at the end of the specimens. This is because the strength of the skin of the cavity formed after core-back is relatively low in the case of insufficient material, the gas in the cavity breaks through the skin when the pressure rises to a certain extent, and generates the holes as shown in Figure $6 \mathrm{~b}$. The gas in the cavity spills from the holes and is discharged through the mold exhaust system, which causes the cavity structure to be destroyed, making the supposed integrity of the shape cannot continue to remain intact, resulting in collapse. Holding is carried out when the cavity collapses, although the newly injected melt can re-prop up the collapsed part, at this stage the skin has begun to cool and the folds caused by the collapse are difficult to fully flatten. In addition, some of the newly injected melts would also spill over from the holes, which results in the appearance of rough and wrinkled surface of the specimens as shown in Figure 6a with the shot sizes of 56 and $58 \mathrm{~mm}$. When the shot sizes are 60 and $62 \mathrm{~mm}$, respectively, the shape of the specimens are intact, the surfaces are smooth and wrinkle-free, but from Figure $6 \mathrm{c}$, it can be seen that when the shot size is $62 \mathrm{~mm}$, the specimen has burrs.

When the injection speed is used as the single variable, the other parameters are fixed, where the blowing agent content is $7 \%$, the mold temperature is $50{ }^{\circ} \mathrm{C}$, the shot size is $60 \mathrm{~mm}$, the first stage holding pressure is $5 \mathrm{MPa}$, the first stage holding time is $3 \mathrm{~s}$, the second stage holding pressure is $18 \mathrm{MPa}$, the second stage holding time is $0.5 \mathrm{~s}$ and the core-back rate is $7 \mathrm{~mm} / \mathrm{s}$.

Figure 7 shows 3D outlines of specimen surfaces obtained at injection speed of $95,100,105$ and $110 \mathrm{~mm} / \mathrm{s}$,

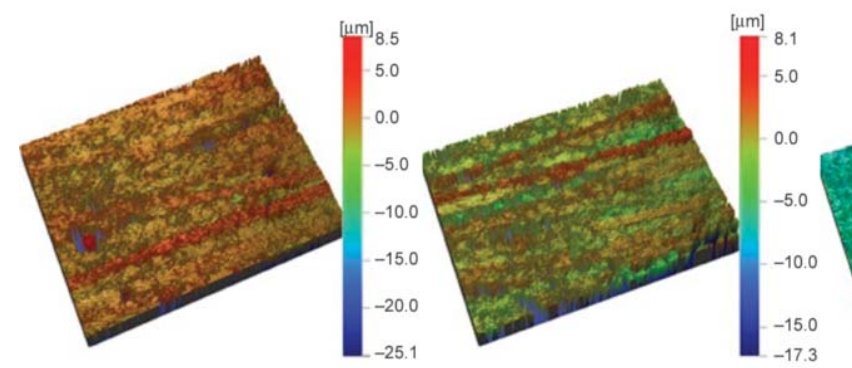

a)

\begin{abstract}
$95 \mathrm{~mm} / \mathrm{s}$
\end{abstract}
b)

\begin{abstract}
$100 \mathrm{~mm} / \mathrm{s}$
\end{abstract}
c)

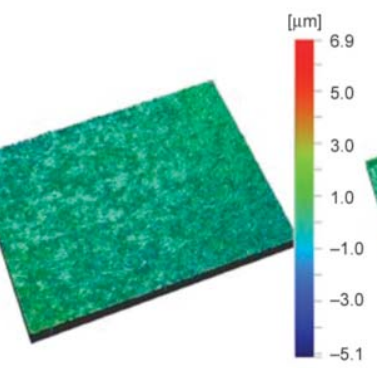

$105 \mathrm{~mm} / \mathrm{s}$

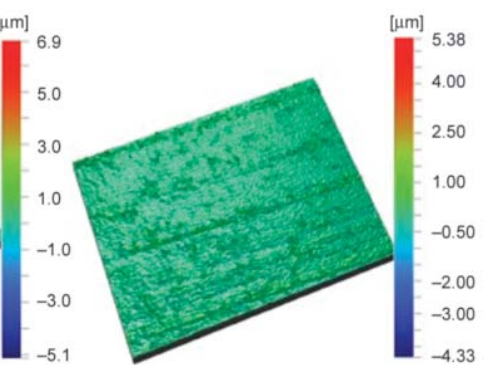

$110 \mathrm{~mm} / \mathrm{s}$

Figure 7. 3D outlines of specimen surfaces at different injection speeds. a) 3D outline at injection speed of $95 \mathrm{~mm} / \mathrm{s}$, b) 3D outline at injection speed of $100 \mathrm{~mm} / \mathrm{s}, \mathrm{c}) 3 \mathrm{D}$ outline at injection speed of $105 \mathrm{~mm} / \mathrm{s}, \mathrm{d}$ ) 3D outline at injection speed of $110 \mathrm{~mm} / \mathrm{s}$. 
respectively. It can be seen from 3D outlines that the surface quality of the specimen increases with the increase of injection speed. However, it was also found by experiments that when the injection speed was $110 \mathrm{~mm} / \mathrm{s}$, there was a burr near the gate. This is because the injection pressure increases as the injection speed increases, and the increase of injection pressure results in excessive melt pressure near the gate, causing a burr appearing.

\subsection{Influence of holding}

\subsubsection{Influence of the first stage holding}

1) Influence of the first stage holding pressure

When the first stage holding pressure is used as the single variable, the other parameters are fixed, where the blowing agent content is $7 \%$, the mold temperature is $50^{\circ} \mathrm{C}$, the shot size is $60 \mathrm{~mm}$, the injection speed is $105 \mathrm{~mm} / \mathrm{s}$, the first stage holding time is $3 \mathrm{~s}$, the second stage holding pressure is $0 \mathrm{MPa}$, the second stage holding time is $0 \mathrm{~s}$ and the core-back rate is $7 \mathrm{~mm} / \mathrm{s}$.

Figure 8 shows the SEM photographs of the cells and the internal flow front of the specimens under first stage holding pressures of $0,1,3,5$ and $7 \mathrm{MPa}$, respectively. From the SEM photographs of the cells shown in Figure 8a, it can be seen that the cell radius of the specimens decreases gradually with the increase of first stage holding pressure. This is because in the new core-back method adopted in this paper, the effect of the first stage holding is to inject new polymer melt into the 'cavity structure' formed by core-back stage. The higher the holding pressure, the faster the polymer melt is injected into the 'cavity structure', which is the same as increasing injection speed in conventional injection molding. In this way, it is beneficial to obtain uniform cell size and larger foaming rate. In addition, it can be seen from Figure $8 \mathrm{a}$ that when the first stage holding pressure is not higher than $5 \mathrm{MPa}$, the cell density of the specimen increases with the increasing of the holding pressure. However, when the first stage holding pressure reaches $7 \mathrm{MPa}$, the cell density is lower than that of the specimen at $5 \mathrm{MPa}$. In order to explain this phenomenon, the internal short shot specimens with the holding pressure of $0,1,3,5$ and $7 \mathrm{MPa}$ were obtained by adjusting the holding time of the first stage holding and canceling the second stage holding. At the same time, photographs of the flow front inside the specimens and SEM photographs of the internal flow front surfaces were also taken, as shown in Figure $8 \mathrm{~b}$ and $8 \mathrm{c}$. It can be seen from Figure $8 \mathrm{~b}$ and $8 \mathrm{c}$ that the internal flow front surfaces are relatively smooth when the holding pressure is lower than $5 \mathrm{MPa}$, and there is a depression on the surface of the flow front when the first stage holding pressure is lower. This is because the new method used in this paper can spontaneously apply gas counter pressure (GCP) on the melt flow front during the secondary
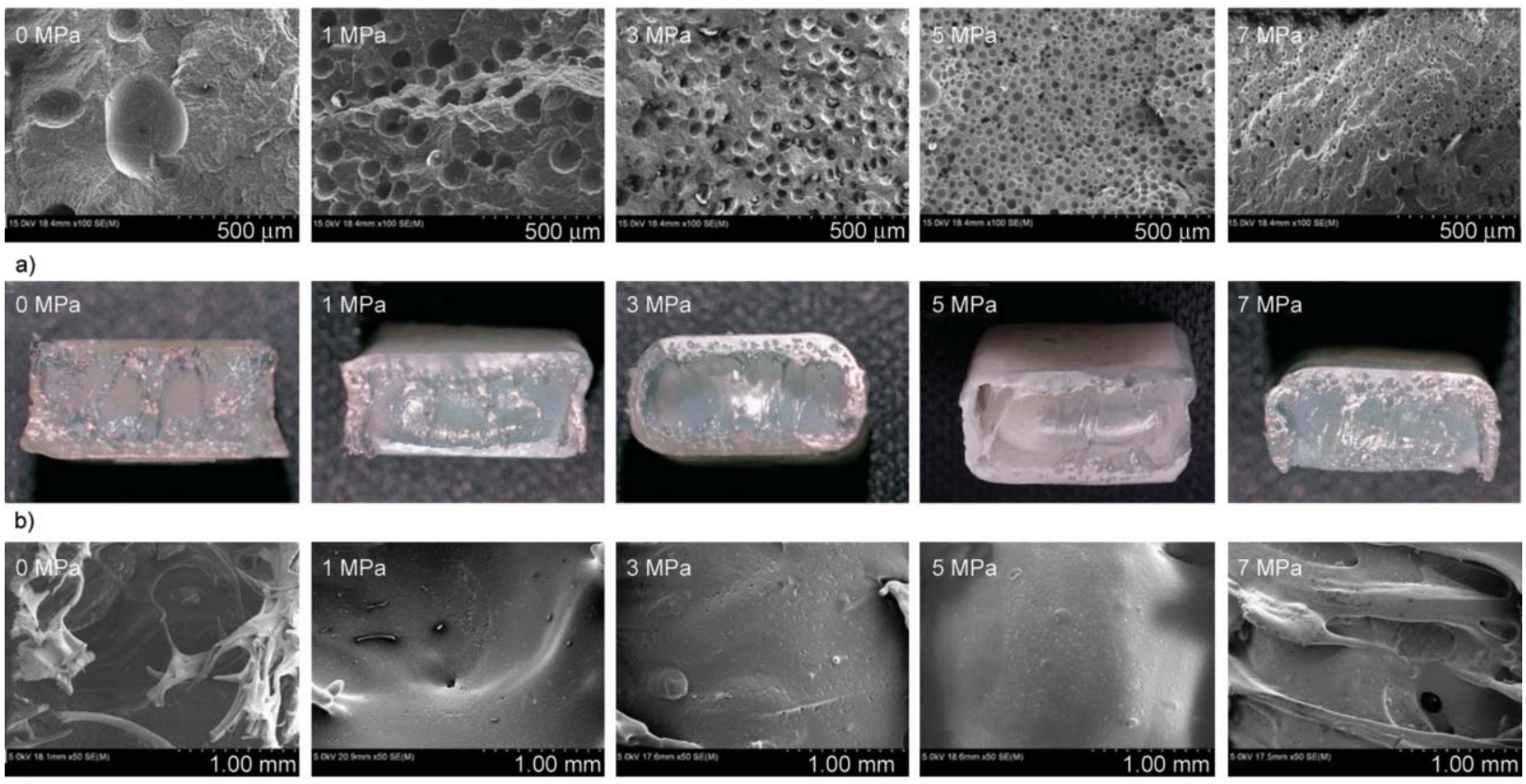

c)

Figure 8. Cells and internal flow front of the specimens under different first stage holding pressures, (a) SEM photographs of cells, (b) photographs of the internal flow front, (c) SEM photographs of the internal flow front the surfaces. 
injection stage. When the injection pressure is low, the flow front will be depressed by the spontaneous GCP. When the first stage holding pressure is $5 \mathrm{MPa}$, the internal flow front's surface is smooth and has no depression, which is similar to the flow front of the conventional injection foam after applying GCP. When the first stage holding pressure is not higher than $5 \mathrm{MPa}$, the internal flow front's surface is smooth, which indicates that there is no gas overflowing due to the spring effect during the filling process. In this case, the effect of filling rate determined by the first stage holding pressure on the cells is similar to that of the traditional injection foaming. In other words, with the increase of filling rate, the cell size is more uniform and the cell density is larger. When the first stage holding pressure is higher than $5 \mathrm{MPa}$, the internal flow front surfaces are very rough. It can be clearly seen that the rough surfaces are formed by the spring effect. This is because the filling rate is too fast when the first stage holding pressure is too high, and the pressure of the polymer melt flow is higher than that at the spontaneous GCP, which makes the spring effect obvious in the filling process. Under the action of the spring effect, the gas in the melt overflows, so that the amount of gas that participates in nucleation is reduced, ultimately leading to a decrease in cell density. While the excessive pressure limits the growth of cells, it also limits the nucleation to some extent.

\section{2) Influence of the first stage holding time}

When the first stage holding time is used as the single variable, the other parameters are fixed, where the blowing agent content is $7 \%$, the mold temperature is $50{ }^{\circ} \mathrm{C}$, the shot size is $60 \mathrm{~mm}$, the injection speed is $105 \mathrm{~mm} / \mathrm{s}$, the first stage holding pressure is $5 \mathrm{MPa}$, the second stage holding pressure is $0 \mathrm{MPa}$, the second stage holding time is $0 \mathrm{~s}$ and the core-back rate is $7 \mathrm{~mm} / \mathrm{s}$.

In order to determine the effect of the first stage holding time on the melt filling process, it is necessary to obtain the internal short shot specimens. Therefore, in this group of experiments, the second stage holding was cancelled. Figure 9 shows the filling behavior of the specimens under the first stage holding time of $0,0.5,1,1.5,2,2.5$ and $3 \mathrm{~s}$, respectively. Figure $9 \mathrm{a}$ shows the photograph of the internal filling situation of specimens at different holding time. It can be measured from the photograph that the filling rates of the specimens were 27, 61, 70, 77, 86, 94 and $100 \%$ for the holding time of $0,0.5,1,1.5,2,2.5$ and $3 \mathrm{~s}$, respectively. It is obvious that the filling rate increases with the increase of the first stage holding time. When the first stage holding time reaches $3 \mathrm{~s}$, the specimen has been filled completely. From the relationship curve of the filling rate and the holding time as shown in Figure 9b, it can be seen more clearly that the filling rate increases with the holding time. In addition, it can also be found from Figure 9a that the filling rate is not $0 \%$ for the holding time of $0 \mathrm{~s}$. This is because in the process of injection molding, the pressure and material portion of the specimen near the gate is higher than that away from the gate. Even if no holding is maintained, the polymer melt near the gate will still foam, expand, and fill the cavity to a certain extent. This results in the fact that the filling rate of specimen is not $0 \%$ under non holding condition.
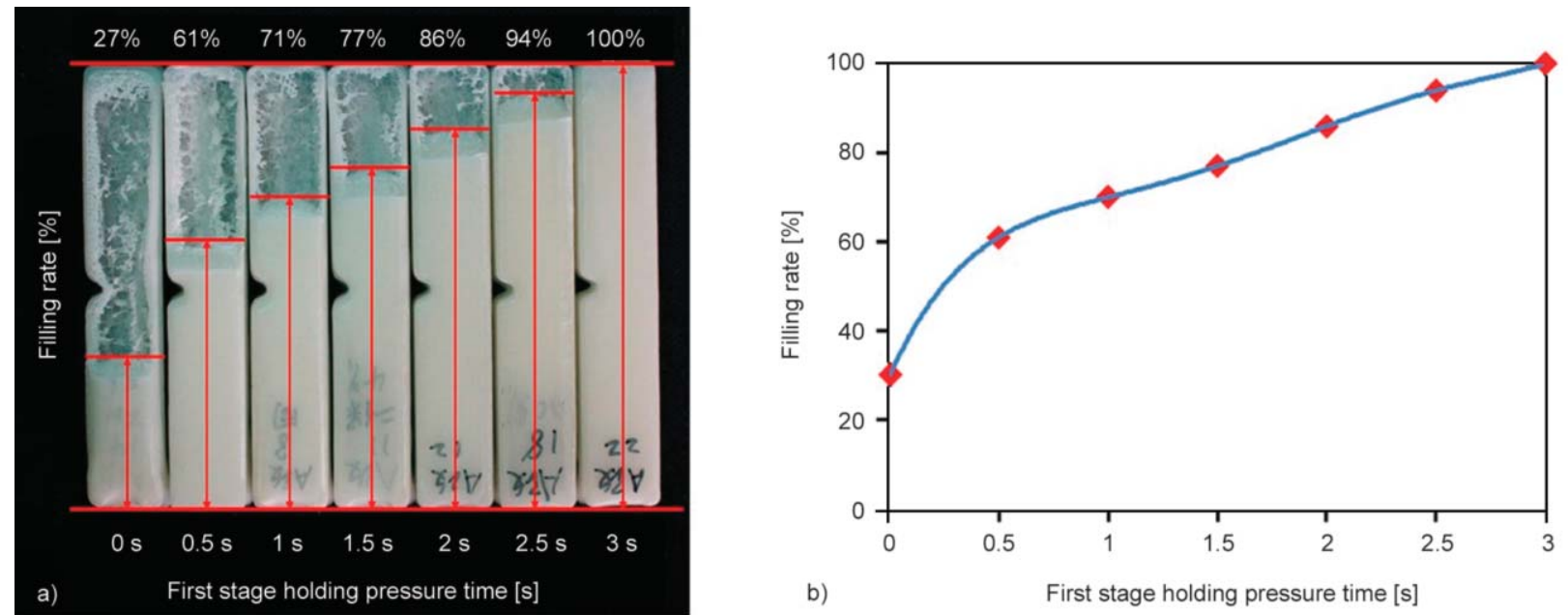

Figure 9. Filling conditions of specimens with different first stage holding times, (a) photograph of the internal filling situation of the specimens, (b) the relationship curve of the filling rate and the holding time. 


\subsubsection{Influence of the second stage holding}

1) Influence of the second stage holding pressure

When the second stage holding pressure is used as the single variable, the other parameters are fixed, where the blowing agent content is $7 \%$, the mold temperature is $50{ }^{\circ} \mathrm{C}$, the shot size is $60 \mathrm{~mm}$, the injection speed is $105 \mathrm{~mm} / \mathrm{s}$, the first stage holding pressure is $5 \mathrm{MPa}$, the first stage holding time is $3 \mathrm{~s}$, the second stage holding time is $0.5 \mathrm{~s}$ and the core-back rate is $7 \mathrm{~mm} / \mathrm{s}$.

Figure 10 shows the SEM photos of the internal cells of the specimens under the second stage holding pressures of 0,18 and $24 \mathrm{MPa}$, and the photos of the gate tip of the specimens under the second stage holding pressures of 12 and $18 \mathrm{MPa}$, respectively. From Figure $10 \mathrm{a}-10 \mathrm{c}$, it can be seen that when the second stage holding pressure is $0 \mathrm{MPa}$, the cell size in the specimen is larger and the cell density is lower. This is because although there is enough space for foaming, the foaming capacity of the chemical blowing agent is insufficient and the gas content is low. Under the action of surface tension, the gas in smaller cells will diffuse into larger ones, resulting in the overgrowth of larger cells and the disappearance of smaller ones. When the second stage holding pressure reaches $24 \mathrm{MPa}$, due to the excessive high pressure, the foaming capacity of the chemical blowing agent is insufficient and the gas content is low too, the smaller cells also disappear. At the same time, it can be seen from the photos that the larger cells undergo a certain degree of deformation under high pressure, which is not as smooth as that of cells in the specimen under the second stage holding pressure of $18 \mathrm{MPa}$. Figure 10d gives the photo of the gate location of the specimens with the second stage holding pressure of 12 and $18 \mathrm{MPa}$, respectively, it can be seen from the photograph that when the second stage holding pressure is $12 \mathrm{MPa}$, the specimen's gate appears obvious sink mark. This is because the skin formed during the core-back stage has cooled and has a certain of intensity at the holding stage, when the second stage holding pressure is insufficient, it is difficult to compensate for the sink mark.

\section{2) Influence of the second stage holding time}

When the second stage holding time is used as the single variable, the other parameters are fixed, where the blowing agent content is $7 \%$, the mold temperature is $50^{\circ} \mathrm{C}$, the shot size is $60 \mathrm{~mm}$, the injection speed is $105 \mathrm{~mm} / \mathrm{s}$, the first stage holding pressure is $5 \mathrm{MPa}$, the first stage holding time is $3 \mathrm{~s}$, the second stage holding pressure is $18 \mathrm{MPa}$ and the coreback rate is $7 \mathrm{~mm} / \mathrm{s}$.

Figure 11 gives the SEM photographs of the internal cells in the specimens when the second stage holding time is $0,0.5$ and $1 \mathrm{~s}$, respectively, where the SEM photograph for the second stage holding time of $0 \mathrm{~s}$ and the stage holding pressure of $0 \mathrm{MPa}$ are the same. This is because the holding pressure of $0 \mathrm{MPa}$ or the holding time of $0 \mathrm{~s}$ is equivalent to no second stage holding, that is, the holding pressure of $0 \mathrm{MPa}$ and the holding time of $0 \mathrm{~s}$ have the same function. When the second stage holding time is $1 \mathrm{~s}$, due to the foaming ability of the chemical blowing agent is insufficient and the gas content is low, the smaller cells disappear under the long holding time. At the same time, it is also found that, similar to increasing the second stage holding pressure, prolonging the second stage holding time will also cause larger cells generate deformation to a certain degree.

\subsection{Influence of core-back rate}

When the core-back rate is used as the single variable, the other parameters are fixed, where the blowing agent content is $7 \%$, the mold temperature is $50^{\circ} \mathrm{C}$, the shot size is $60 \mathrm{~mm}$, the injection speed is $105 \mathrm{~mm} / \mathrm{s}$, the first stage holding pressure is $5 \mathrm{MPa}$, the first stage holding time is $3 \mathrm{~s}$, the second stage
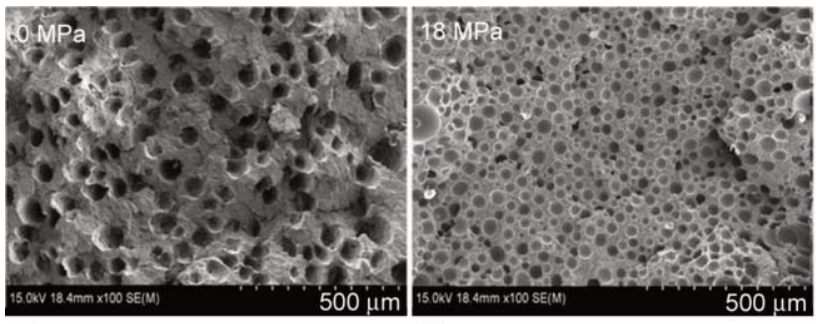

b)
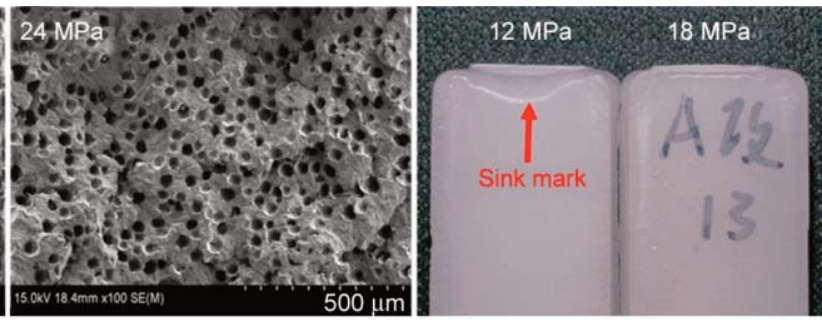

Figure 10. SEM photos of the internal cells under different second stage holding pressures, $(\mathrm{a}-\mathrm{c})$ SEM photos of internal cells, (d) photo of the gate location of the specimens for the second stage holding pressure of 12 and $18 \mathrm{MPa}$. 


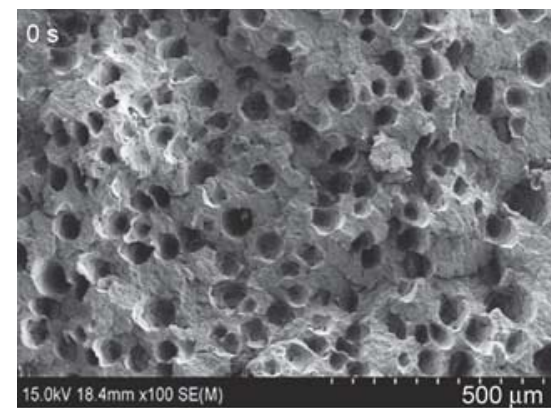

a)

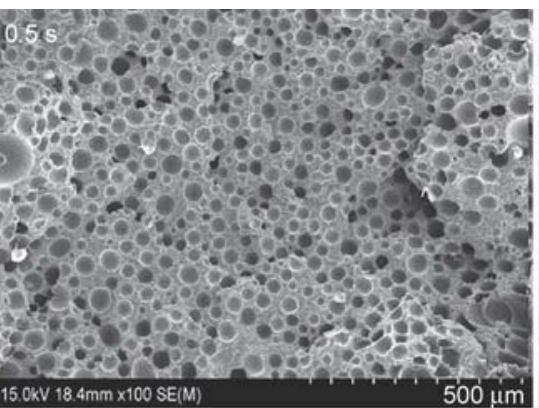

b)

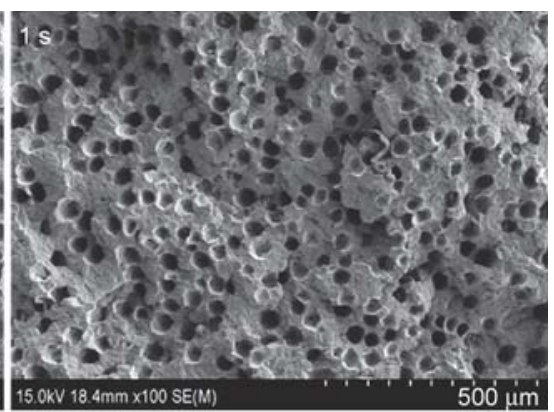

c)

Figure 11. SEM photographs of the internal cells with different second stage holding time. a) $0 \mathrm{~s}, \mathrm{~b}) 0.5 \mathrm{~s}$, c) $1 \mathrm{~s}$.

holding pressure is $18 \mathrm{MPa}$ and the second stage holding time is $0.5 \mathrm{~s}$.

Figure 12 shows the appearance and internal structure of the specimens when core-back rate is $1 \mathrm{~mm} / \mathrm{s}$, $3,5,7$ and $9 \mathrm{~mm} / \mathrm{s}$, respectively. It can be seen from Figure $12 \mathrm{a}$ and $12 \mathrm{~b}$ that, with the increase of coreback rate, the appearance of the specimens are gradually intact. When the core-back rate is less than $7 \mathrm{~mm} / \mathrm{s}$, the shape of the mold cavity cannot be completely replicated. In addition, Figure $12 \mathrm{~d}-12 \mathrm{~h}$ shows the SEM photos of the specimens' internal structure near the flow end under different core-back rates. It can be seen from Figure $12 \mathrm{~d}-12 \mathrm{f}$ that, when the coreback rate is $1 \mathrm{~mm} / \mathrm{s}$, there are hardly any cells in the specimens. When the core-back rate is less than $7 \mathrm{~mm} / \mathrm{s}$, there is no unique skin region, as shown in Figure $12 \mathrm{~g}$ and $12 \mathrm{~h}$. The unique skin region is only obtained by using the new method used in this experiment. This is because the specimen initial thickness is small (only $1.8 \mathrm{~mm}$ ), and its cooling rate is relatively high. When the core-back rate is too low, the skin of the cavity structure is cooled down and solidified before the end of core-back and could not be completely formed at all. At this moment, the melt cavity can no longer be enlarged by the action force produced by core-back and foaming of polymer, which makes the skin of the cavity structure unable to closely fit the surface of the mold cavity, so that the shape of the mold cavity cannot be completely replicated. In addition, the new melt cannot be filled in the incompletely formed cavity structure, which leads to the unique skin region unable to form. When the core-back rate is $7 \mathrm{~mm} / \mathrm{s}$, the skin of the cavity structure is not completely cooled before the end of core-back. The cavity can be expanded to fully adhere to the inner surface of the mold cavity by the force produced by the force produced by core-back and foaming of polymer, and the specimens with complete replica mold cavity shape can be obtained. Therefore, when the cooling rate of polymer melt is constant, the appropriate increase of the core-back rate can make the parts copy the shape of mold cavity

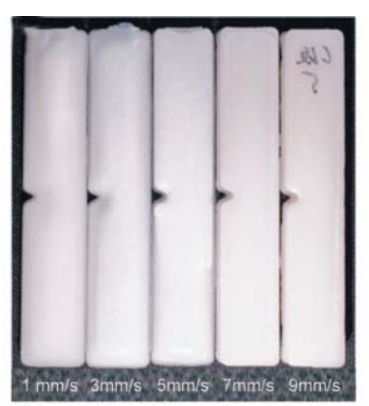

a)

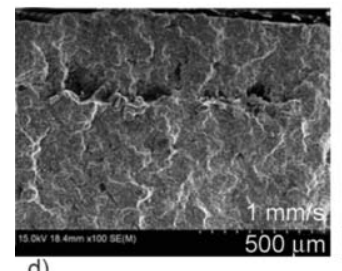

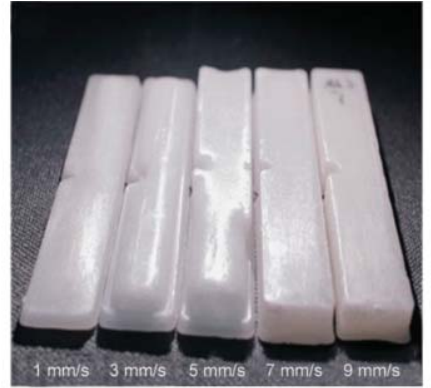

b)

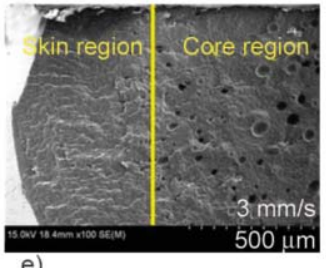

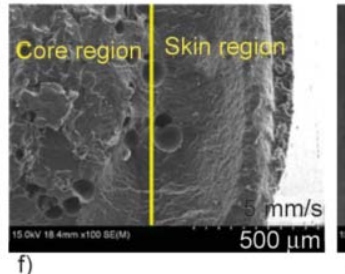

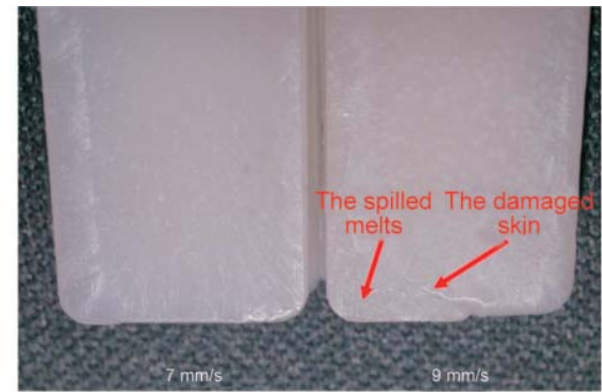

c)

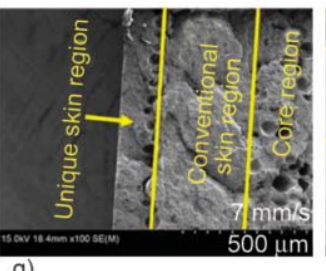

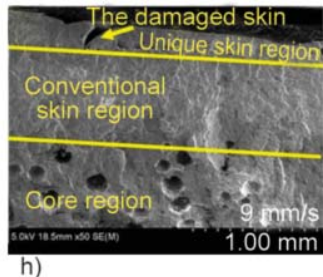

h)

Figure 12. Appearance and internal structure of the specimens under different core-back rates. (a-b) specimens under different core-back rates, c) specimens under core-back rate of 7 and $9 \mathrm{~mm} / \mathrm{s},(\mathrm{d}-\mathrm{h})$ SEM photos of the specimens' internal structure near the flow end under different core-back rates. 
better. However, it can be seen from the comparison of the specimen details at core-back rates of 7 and $9 \mathrm{~mm} / \mathrm{s}$ given in Figure 12c and the internal structure of the specimen at core-back rates of $9 \mathrm{~mm} / \mathrm{s}$ given in Figure 12h, respectively, that when the core-back rate reaches $9 \mathrm{~mm} / \mathrm{s}$, the specimen's skin ruptures and the polymer melt overflows from the cavity, which is similar to the appearance of the specimen when the injection volume is too low shown in Figure 6. However, it is different from the cortical rupture caused by low injection volume. The cortical rupture occurring here is because the temperature of polymer melt is still higher during the core-back process when the core-back rate is too fast, causing the strength of skin structure of the cavity to be insufficient for a certain period of time. This relatively weak skin may rupture under the pulling force of core-back and polymer foaming, and during the next stage of holding, some of the newly injected polymer melt will overflow through the damaged skin.

\subsection{Mechanical properties and weight reduction}

Based on the above results, when the blowing agent content is $7 \%$, the mold temperature is $50{ }^{\circ} \mathrm{C}$, the shot size is $60 \mathrm{~mm}$, the injection speed is $105 \mathrm{~mm} / \mathrm{s}$, the first stage holding pressure is $5 \mathrm{MPa}$, the first stage holding time is $3 \mathrm{~s}$, the second stage holding pressure is $18 \mathrm{MPa}$, the second stage holding time is $0.5 \mathrm{~s}$ and the core-back rate is $7 \mathrm{~mm} / \mathrm{s}$, the foamed plastic parts with $100 \%$ filling ratio and different density can be obtained only by changing the second stage holding time. In addition, because the effect when the second stage holding time is $0 \mathrm{~s}$ is the same as that when the second stage holding pressure is $0 \mathrm{MPa}$, they are both equivalent to no second stage holding. In this case, the gate of the specimens will collapse, and the specimens cannot duplicate the shape of the mold cavity completely. Therefore, the second stage holding time is selected to be $0.1,0.3$, $0.5,0.7$ and $1 \mathrm{~s}$.

When the second stage holding time is $0.1 \mathrm{~s}$, the density of the foamed plastics is $0.49 \mathrm{~g} / \mathrm{cm}^{3}$, and the weight loss rate is $46 \%$. The tensile strength, elastic modulus, and notch impact strength are $9 \mathrm{MPa}$, $833 \mathrm{MPa}$, and $58 \mathrm{~J} / \mathrm{m}$ respectively. The specific tensile strength, specific elastic modulus, and specific notch impact strength are $0.018 \mathrm{Nm} / \mathrm{kg}, 1.7 \mathrm{Nm} / \mathrm{kg}$ and $0.12 \mathrm{Jm}^{2} / \mathrm{kg}$, respectively.
When the second stage holding time is $0.3 \mathrm{~s}$, the density of the foamed plastics is $0.56 \mathrm{~g} / \mathrm{cm}^{3}$, and the weight loss rate is $38 \%$. The tensile strength, elastic modulus, and notch impact strength are $13.4 \mathrm{MPa}$, $1090 \mathrm{MPa}$ and $81 \mathrm{~J} / \mathrm{m}$, respectively. The specific tensile strength, specific elastic modulus, and specific notch impact strength are $0.024 \mathrm{Nm} / \mathrm{kg}, 1.9 \mathrm{Nm} / \mathrm{kg}$ and $0.14 \mathrm{Jm}^{2} / \mathrm{kg}$, respectively.

When the second stage holding time is $0.5 \mathrm{~s}$, the density of the foamed plastics is $0.64 \mathrm{~g} / \mathrm{cm}^{3}$, and the weight loss rate is $29 \%$. The tensile strength, elastic modulus, and notch impact strength are $16.7 \mathrm{MPa}$, $1302 \mathrm{MPa}$ and $98 \mathrm{~J} / \mathrm{m}$ respectively. The specific tensile strength, specific elastic modulus, and specific notch impact strength are $0.026 \mathrm{Nm} / \mathrm{kg}, 2.0 \mathrm{Nm} / \mathrm{kg}$ and $0.15 \mathrm{Jm}^{2} / \mathrm{kg}$, respectively.

When the second stage holding time is $0.7 \mathrm{~s}$, the density of the foamed plastics is $0.7 \mathrm{~g} / \mathrm{cm}^{3}$, and the weight loss rate is $22 \%$. The tensile strength, elastic modulus, and notch impact strength are $16.9 \mathrm{MPa}, 1331 \mathrm{MPa}$ and $100 \mathrm{~J} / \mathrm{m}$ respectively. The specific tensile strength, specific elastic modulus, and specific notch impact strength are $0.024 \mathrm{Nm} / \mathrm{kg}, 1.9 \mathrm{Nm} / \mathrm{kg}$ and $0.14 \mathrm{Jm}^{2} / \mathrm{kg}$, respectively.

When the second stage holding time is $1 \mathrm{~s}$, the density of the foamed plastics is $0.76 \mathrm{~g} / \mathrm{cm}^{3}$, and the weight loss rate is $16 \%$. The tensile strength, elastic modulus, and notch impact strength are $17 \mathrm{MPa}$, $1366 \mathrm{MPa}$ and $101 \mathrm{~J} / \mathrm{m}$ respectively. The specific tensile strength, specific elastic modulus, and specific notch impact strength are $0.022 \mathrm{Nm} / \mathrm{kg}, 1.8 \mathrm{Nm} / \mathrm{kg}$ and $0.13 \mathrm{Jm}^{2} / \mathrm{kg}$, respectively.

Figure 13 shows the specific strength and weight reduction curves of specimens for the second stage holding time of $0.1,0.3,0.5,0.7$ and $1 \mathrm{~s}$, respectively. It can be seen that the specific tensile strength, specific elastic modulus, and specific notch impact strength increase firstly and then decrease with the increase of holding time. When the second stage holding time is $0.5 \mathrm{~s}$, the specific strength of the specimens reaches the highest. However, the weight loss rate decreases with the increase of the second stage holding time. This is because with the increase of the second stage holding time, some cells become smaller or even disappear under the holding pressure, which makes more melt injected into the cavity structure, and ultimately increases the density of the specimens. In addition, the weight loss rate of the specimens foamed by the conventional chemical injection molding was 

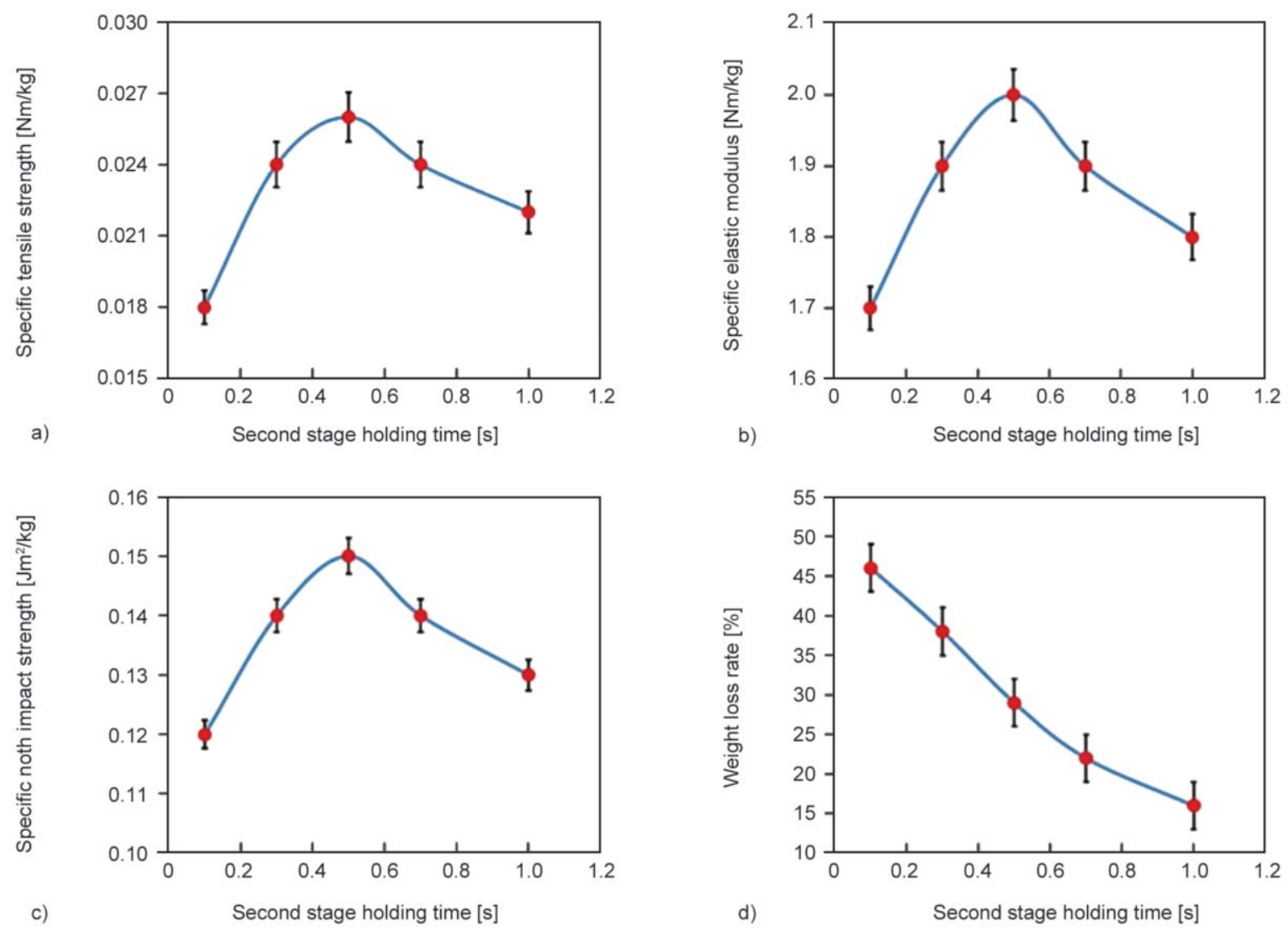

Figure 13. Specific strength and weight reduction curves of specimens under different second stage holding time, (a) curve of specific tensile strength, (b) curve of specific elastic modulus, (c) curve of specific notch impact strength, (d) curve of weight loss rate.

only $11 \%$, the tensile strength was $14 \mathrm{MPa}$, the elastic modulus was $1140 \mathrm{MPa}$, the notch impact strength was $79 \mathrm{~J} / \mathrm{m}$, the specific tensile strength was $0.018 \mathrm{Nm} / \mathrm{kg}$, the specific elastic modulus was $1.4 \mathrm{Nm} / \mathrm{kg}$, and the specific notch impact strength with was $0.10 \mathrm{Jm}^{2} / \mathrm{kg}$. Compared with the conventional injection foamed specimens, the maximum weight loss rate of the specimens obtained by the new method increased by $318 \%$, the maximum tensile strength increased by $21 \%$, the maximum elastic modulus increased by $20 \%$, the maximum notch impact strength increased by $28 \%$, the maximum specific tensile strength increased by $44 \%$, the maximum specific elastic modulus increased by $43 \%$, and the maximum specific notch impact strength increased by $50 \%$, respectively.

\section{Conclusions}

In this paper, the experiments on the new core-back chemical foam injection molding method previously proposed were carried out by taking blowing agent content [\%], mold temperature $\left[{ }^{\circ} \mathrm{C}\right]$, shot size $[\mathrm{mm}]$, injection speed $[\mathrm{mm} / \mathrm{s}]$, holding pressure $[\mathrm{MPa}]$, holding pressure time $[\mathrm{s}]$ and core-back rate $[\mathrm{mm} / \mathrm{s}$ ] as single variables. The influence of the above parameters on the process was studied in detail and their influencing mechanisms were revealed deeply. The relationships of the parameters with the mechanical properties and the weight reduction effect of the specimens were obtained. The following main conclusions were drawn.

(1) The optimum AC blowing agent content is $7 \%$. When the blowing agent content is too low, low blowing agent contention will result in insufficient foaming power and poor foaming effect. When the blowing agent content is too high, the exothermic reaction produced by decomposition of excessive AC blowing agent will reduce the strength of polymer melt and destroy the formed cell structure. In addition, excessive heat also inhibits the decomposition of AC blowing agent, which results in some of the blowing agents cannot be completely decomposed. The undissolved blowing agents are dispersed in the plastic matrix, resulting in a yellowing appearance of the plastic parts. Mold temperature affects the 
surface quality of plastic parts. With the increase of mold temperature, the ability of polymer melt to copy the mold cavity surface is gradually enhanced, and the surface quality of plastic parts is gradually improved. However, too high mold temperature can also cause plastic parts to produce burrs.

(2) The main function of shot size is to control the strength of the skin, which is unique to the new method. When the shot size is too low, the low shot size will reduce the strength of the skin, causing the skin to rupture in the next filling stage and ultimately affect the appearance of the plastic parts. However, when the shot size is too high, it will cause plastic parts to produce burrs because there are too many melts injected into the mold cavity at the initial stage. The main function of injection speed is to affect the surface quality of plastic parts. With the increase of injection speed, the surface quality of plastic parts is gradually improved. However, the excessive injection speed will cause excessive pressure at the gate and result in burr. The shot size and injection speed are the important parameters of the first stage of the new method, because this stage is the same as conventional foam injection molding, the effects of shot size and injection speed are the same as those of conventional injection molding.

(3) The holding stage of the new method is divided into two stages: the first stage holding and second stage holding. The first stage holding affects the polymer melt filling cavity structure and the cell structure in the specimens. In the second filling stage peculiar to the new method, the effect of the first stage holding is similar to shot size and injection speed of conventional injection molding. The first stage holding pressure determines the filling speed and the first stage holding time determines the filling rate of the secondary filling stage. The second stage holding determines the size and quantity of the cells finally, and compensates the shrinkage of plastic parts. In the secondary filling stage peculiar to the new method, the effect of the second holding is similar to the holding process of the conventional injection molding.
(4) The main function of core-back rate is to control the cortical shape of the cavity structure peculiar to the new method. When the core-back rate is too low, due to the cooling of the melt, the skin structure of the cavity is cooled down and fixed before the end of core-back, which makes it difficult for plastic parts to replicate the shape of the mold cavity. However, when the core-back rate is too high, the melt cannot obtain enough cooling time. Thus, in the whole core-back process, the temperature of the melt is too high and the strength is insufficient, leading to the rupture of the cavity structure.

(5) The lowest weight loss rate of plastic parts obtained by the new core-back method is $16 \%$, and the highest is $46 \%$. Compared with the conventional foam injection molding method, the new core-back method can produce the specimens with higher weight loss rate, better mechanical properties, and higher specific strength.

\section{Acknowledgements}

The authors are grateful to the National Natural Science Foundation of China (NSFC, Grant No. 51875318) and the Young Scholars Program of Shandong University (Grant No. 2017WLJH23).

\section{References}

[1] Shaayegan V., Wang C., Costa F., Han S., Park C. B.: Effect of the melt compressibility and the pressure drop rate on the cell-nucleation behavior in foam injection molding with mold opening. European Polymer Journal, 92, 314-325 (2017). https://doi.org/10.1016/j.eurpolymj.2017.05.003

[2] Wang G., Zhao J., Yu K., Mark L H., Wang G., Gong P., Park C. B., Zhao G.: Role of elastic strain energy in cell nucleation of polymer foaming and its application for fabricating sub-microcellular TPU microfilms. Polymer, 119, 28-39 (2017).

https://doi.org/10.1016/j.polymer.2017.05.016

[3] Lee J. W. S., Wang J., Yoon J. D., Park C. B.: Strategies to achieve a uniform cell structure with a high void fraction in advanced structural foam molding. Industrial and Engineering Chemistry Research, 47, 9457-9464 (2008). https://doi.org/10.1021/ie0707016

[4] Shaayegan V., Ameli A., Wang S., Park C. B.: Experimental observation and modeling of fiber rotation and translation during foam injection molding of polymer composites. Composites Part A: Applied Science and Manufacturing, 88, 67-74 (2016). https://doi.org/10.1016/j.compositesa.2016.05.013 
[5] Wong S., Lee J. W. S., Naguib H. E., Park C. B.: Effect of processing parameters on the mechanical properties of injection molded thermoplastic polyolefin (TPO) cellular foams. Macromolecular Materials and Engineering, 293, 605-613 (2008).

https://doi.org/10.1002/mame.200700362

[6] Shaayegan V., Mark L. H., Tabatabaei A., Park C. B.: A new insight into foaming mechanisms in injection molding via a novel visualization mold. Express Polymer Letters, 6, 462-469 (2016).

https://doi.org/10.3144/expresspolymlett.2016.44

[7] Ohshima M., Kubota M., Ishihara S., Hikima Y., Sato A., Sekiguchi T.: Microcellular foam injection molding with cellulose nanofibers (CNFs). Aip Conference Proceedings. 1713, 100001/1-100001/4 (2016).

https://doi.org/10.1063/1.4942306

[8] Yusa A., Yamamoto S., Goto H., Uezono H., Asaoka F., Wang L., Ando M., Ishihara S., Ohshima M.: A new microcellular foam injection-molding technology using non-supercritical fluid physical blowing agents. Polymer Engineering and Science, 57, 105-113 (2017). https://doi.org/10.1002/pen.24391

[9] Wang L., Ishihara S., Ando M., Minato A., Hikima Y., Ohshima M.: Fabrication of high expansion microcellular injection-molded polypropylene foams by adding long-chain branches. Industrial and Engineering Chemistry Research, 55, 11970-11982 (2016).

https://doi.org/10.1021/acs.iecr.6b03641

[10] Wang G., Zhao G., Dong G., Mu Y., Park C. B., Wang G.: Lightweight, super-elastic, and thermal-sound insulation bio-based PEBA foams fabricated by high-pressure foam injection molding with mold-opening. European Polymer Journal, 103, 68-79 (2018).

https://doi.org/10.1016/j.eurpolymj.2018.04.002

[11] Shaayegan V., Mark L. H., Park C. B., Wang G.: Identification of cell-nucleation mechanism in foam injection molding with gas-counter pressure via mold visualization. AIChE Journal, 62, 4035-4046 (2016). https://doi.org/10.1002/aic.15433

[12] Chen S-C., Hsu P-S., Hwang S-S.: The effects of gas counter pressure and mold temperature variation on the surface quality and morphology of the microcellular polystyrene foams. Journal of Applied Polymer Science, 127, 4769-4776 (2013).

https://doi.org/10.1002/app.37994

[13] Chen S. C., Hsu P. S., Lin Y. W.: Establishment of gas counter pressure technology and its application to improve the surface quality of microcellular injection molded parts. International Polymer Processing, 26, 275 282 (2011).

https://doi.org/10.3139/217.2437

[14] Jahani D., Ameli A., Jung P. U., Barzegari M. R., Park C. B., Naguib H.: Open-cell cavity-integrated injectionmolded acoustic polypropylene foams. Materials and Design, 53, 20-28 (2014).

https://doi.org/10.1016/j.matdes.2013.06.063
[15] Stumpf M., Spörrer A., Schmidt H. W., Altstädt V.: Influence of supramolecular additives on foam morphology of injection-molded i-PP. Journal of Cellular Plastics, 47, 519-534 (2011). https://doi.org/10.1177/0021955X11408769

[16] Ruiz J. A. R., Vincent M., Agassant J-F.: Numerical modeling of bubble growth in microcellular polypropylene produced in a core-back injection process using chemical blowing agents. International Polymer Processing, 31, 26-36 (2016).

https://doi.org/10.3139/217.3129

[17] Miyamoto R., Yasuhara S., Shikuma H.: Preparation of micro/nanocellular polypropylene foam with crystal nucleating agents. Polymer Engineering and Science, 54, 2075-2085 (2014).

https://doi.org/10.1002/pen.23758

[18] Wang L., Ando M., Kubota M., Ishihara S., Hikima Y., Ohshima M., Sekiguchi T., Sato A. Yano H.: Effects of hydrophobic-modified cellulose nanofibers (CNFs) on cell morphology and mechanical properties of high void fraction polypropylene nanocomposite foams. Composites Part A: Applied Science and Manufacturing, 98, 166-173 (2017). https://doi.org/10.1016/j.compositesa.2017.03.028

[19] Ishikawa T., Taki K., Ohshima M.: Visual observation and numerical studies of $\mathrm{N}_{2}$ vs. $\mathrm{CO}_{2}$ foaming behavior in core-back foam injection molding. Polymer Engineering and Science, 52, 875-883 (2012).

https://doi.org/10.1002/pen.22154

[20] Spörrer A. N. J., Altstädt V.: Controlling morphology of injection molded structural foams by mold design and processing parameters. Journal of Cellular Plastics, 43, 313-330 (2007). https://doi.org/10.1177/0021955X07079043

[21] Chu R. K. M., Mark L. H., Jahani D., Park C. B.: Estimation of the foaming temperature of mold-opening foam injection molding process. Journal of Cellular Plastics, 52, 619-641 (2016) https://doi.org/10.1177/0021955X15592069

[22] Heim H-P., Tromm M.: General aspects of foam injection molding using local precision mold opening technology. Polymer, 56, 111-118 (2015).

https://doi.org/10.1016/j.polymer.2014.10.070

[23] Lee J. W. S., Lee R. E., Wang J., Jung P. U., Park C. B.: Study of the foaming mechanisms associated with gas counter pressure and mold opening using the pressure profiles. Chemical Engineering Science, 92, 314-325 (2017).

https://doi.org/10.1016/j.ces.2017.04.005

[24] Ameli A., Jahani D., Nofar M., Jung P. U., Park C. B.: Development of high void fraction polylactide composite foams using injection molding: Mechanical and thermal insulation properties. Composites Science and Technology, 90, 88-95 (2014).

https://doi.org/10.1016/j.compscitech.2013.10.019 
[25] Ameli A., Nofar M., Jahani D., Rizvi G., Park C. B.: Development of high void fraction polylactide composite foams using injection molding: Crystallization and foaming behaviors. Chemical Engineering Journal, 262, 78--87 (2015).

https://doi.org/10.1016/j.cej.2014.09.087

[26] Ishikawa T., Ohshima M.: Visual observation and numerical studies of polymer foaming behavior of polypropylene/carbon dioxide system in a core-back injection molding process. Polymer Engineering and Science, 51, 1617-1625 (2011).

https://doi.org/10.1002/pen.21945

[27] Wang L., Ishihara S., Hikima Y., Ohshima M., Sekiguchi T., Sato A., Yano H.: Unprecedented development of ultrahigh expansion injection-molded polypropylene foams by introducing hydrophobic-modified cellulose nanofibers. ACS Applied Materials and Interfaces, 9, 9250-9254 (2017).

https://doi.org/10.1021/acsami.7b01329

[28] Wang G., Zhao G., Wang S., Zhang L., Park C. B.: Injection-molded microcellular PLA/graphite nanocomposites with dramatically enhanced mechanical and electrical properties for ultra-efficient EMI shielding applications. Journal of Materials Chemistry C, 25, 6847 6859 (2018).

https://doi.org/10.1039/C8TC01326H
[29] Wang L., Hikima Y., Ohshima M., Yusa A., Yamamoto S., Goto H.: Unusual fabrication of lightweight injection-molded polypropylene foams by using air as the novel foaming agent. Industrial and Engineering Chemistry Research, 57, 3800-3804 (2018). https://doi.org/10.1021/acs.iecr.7b05331

[30] Reglero Ruiz J. A., Vincent M., Agassant J-F., Claverie A., Huck S.: Morphological analysis of microcellular PP produced in a core-back injection process using chemical blowing agents and gas counter pressure. Polymer Engineering and Science, 55, 2465-2473 (2015).

https://doi.org/10.1002/pen.24136

[31] Wu H., Zhao G., Wang G., Zhang W., Li Y.: A new coreback foam injection molding method with chemical blowing agents. Materials and Design, 144, 331-342 (2018). https://doi.org/10.1016/j.matdes.2018.02.043

[32] Kumar V. J., Suh N. P.: A process for making microcellular thermoplastic parts. Polymer Engineering and Science, 30, 1323-1329 (1990). https://doi.org/10.1002/pen.760302010

[33] Nam G. J., Yoo J. H., Lee J. W.: Effect of long-chain branches of polypropylene on rheological properties and foam-extrusion performances. Journal of Applied Polymer Science, 96, 1793-1800 (2005). https://doi.org/10.1002/app.21619 